FONSECA, Marina Assis; OLIVEIRA, Bernardo Jefferson de. Variações sobre a "cultura científica" em quatro autores brasileiros. História, Ciências, Saúde Manguinhos, Rio de Janeiro, v.22, n.2, abr.-jun. 2015, p.445-459.

\title{
Variações sobre a "cultura científica" em quatro autores brasileiros
}

\section{Variations on the "scientific culture" in four Brazilian authors}

Marina Assis Fonseca

Professora, Instituto de Ciências Biológicas e da Saúde/ Universidade Federal de Viçosa. Rodovia LMG, $818-\mathrm{Km} 6$ 35690-000 - Florestal - MG - Brasil marina.assis@ufv.br

\section{Bernardo Jefferson de Oliveira}

Professor, Faculdade de Educação/Universidade Federal de Minas Gerais. Av. Antônio Carlos, 6.627, sala 1.621, Pampulha 31270-901 - Belo Horizonte - MG - Brasil be@fae.ufmg.br

Recebido para publicação em outubro de 2012. Aprovado para publicação em agosto de 2013.

http://dx.doi.org/10.1590/S0104-59702015005000011
Resumo

A concepção de "cultura científica" varia historicamente, e o exame de suas permanências e transformações pode ajudar a compreender a relação da comunidade científica com a sociedade. As visões do papel da ciência na sociedade vão muito além do avanço de uma determinada forma de conhecimento e seus eventuais ou promissores frutos. Elas envolvem valores, posturas e práticas a difundir e revelam expectativas de avanço social e cultural. Este artigo trata de quatro visões expressivas de diferentes momentos da história brasileira. São apresentadas e analisadas as formulações de quatro autores influentes nas políticas científicas e educacionais do país em diferentes momentos: Miguel Ozorio de Almeida, Anísio Teixeira, Maurício Rocha e Silva e Carlos Vogt.

Palavras-chave: cultura científica; Miguel Ozorio de Almeida (1890-1953); Anísio Teixeira (1900-1971); Maurício Rocha e Silva (1910-1983); Carlos Vogt (1943- ).

Abstract

The concept of "scientific culture" varies historically, and the examination of its continuities and transformations can help us understand the relationship between the scientific community and society. The views on the role of science in society go far beyond the advancement of a particular form of knowledge and its possible or promising fruit. They involve values, postures and practices to be disseminated and reveal expectations of social and cultural advancement. This article discusses four expressive visions of different moments in Brazilian history. The formulations of four influential authors in scientific and educational policies of the country at different times are presented and analyzed: Miguel Ozorio de Almeida, Anísio Teixeira, Maurício Rocha e Silva and Carlos Vogt.

Keywords: scientific culture; Miguel Ozorio de Almeida (1890-1953); Anísio Teixeira (1900-1971); Maurício Rocha e Silva (19101983); Carlos Vogt (1943- ). 
$\mathrm{Q}$ uando se observa a centralidade que a ciência adquiriu em nossa sociedade, percebe-se que ela passou a ser vista como pilar não apenas do desenvolvimento econômico, como também do avanço social e cultural. O desenvolvimento tecnológico é facilmente identificável no aprimoramento dos meios de produção e na maior eficiência do trabalho, mas é discutível que o conhecimento científico tenha sido determinante no desenvolvimento tecnológico dos últimos séculos. No nível do discurso, a interdependência é atestada desde o século XVII, mas, na prática, até o século XX, foram esporádicas e instáveis as relações entre ciência e técnica (Price, Spiegel, 1977; Kranzberg, 1989; Oliveira, 2002). De qualquer forma, essa é uma questão menos controversa do que a da adoção e expansão da perspectiva científica para o conjunto da vida social, ou da ciência como cerne da cultura. Se nos dias de hoje isso parece um desenvolvimento natural do processo civilizatório, quando se observa a história, vê-se que tal processo foi contencioso, repleto de disputas.

Até o final do século XIX, são notáveis as resistências e dúvidas sobre as implicações das ciências na vida social, mesmo na Europa. Embora houvesse muitos defensores da racionalização das instituições (militares, governamentais, médicas, educacionais etc.) com base na perspectiva científica, havia também resistências de diversas ordens.

Ainda que desde o início da modernidade se falasse de uma formação mais prática, ligada à vida mundana, as humanidades clássicas (grego, latim, história, retórica) continuaram preponderantes até o final do século XIX. Nelas se via uma perenidade que as ciências não ofereciam; portanto eram consideradas mais educativas que as cambiantes ciências.

Em um interessante estudo histórico sobre as mudanças no ensino no século XIX, Donnelly (2002) mostra como os defensores da formação humanista desse período criticavam a ciência pelos mesmos motivos que, mais tarde, tornaram-se razões para sua defesa. A autora revela que os defensores de uma educação liberal ou de uma formação humanista se apoiavam justamente nas razões que hoje em dia se apresentam como justificativas para o ensino de ciências: desenvolvimento das capacidades mentais, como raciocínio, observação, comparação, arranjo ordenado das ideias. Mesmo autores ligados à ciência, como Willian Whewell, alimentavam certo ceticismo sobre as funções educacionais das ciências naturais. $\mathrm{Na}$ visão deles, os conhecimentos científicos não tinham a prioridade ou a estabilidade dos estudos clássicos nem tampouco desenvolviam, como a história, a literatura e a filosofia, as desejadas autonomia e compreensão de si e dos outros homens.

Muitos autores advogaram a conveniência de conjugar essas duas culturas. Um discurso que se tornou celebre é o de Charles Percy Snow (1905-1980) As duas culturas (Snow, 1995). O argumento básico é que os cientistas deveriam conhecer mais história, filosofia e artes em geral, enquanto os intelectuais literários deveriam interessar-se mais pelas ciências e suas conquistas. As duas culturas - a humanística e a científica - se enriqueceriam mutuamente, caso ultrapassassem suas fronteiras e limitações. A suprassunção das duas em uma cultura geral ou a "terceira cultura" como solução da dicotomia são temáticas desenvolvidas por outros autores, ainda que sem consenso. Alguns apontam a explosão da literatura de divulgação científica como um sinal dessa conjugação. De fato, vários cientistas se tornaram autores de best-sellers e colunistas de jornais diários.

É provável que o debate em torno da ética na ciência tenha sido incrementado quando a imagem de neutralidade da ciência foi esfacelada nas grandes guerras. Esse debate, porém, 
é realimentado a cada momento em que se anteveem as aplicações e implicações de novas descobertas. De certa forma, valores que antes eram tidos por cognitivos, como objetividade, imparcialidade no julgamento ou testes de verificação intersubjetiva, tornam-se valores sociais. O aprimoramento da vida social passou a ser visto como um desdobramento do pensamento científico aplicado aos domínios da vida prática, não só liberando o homem de restrições da vida física, mas também melhorando suas virtudes morais. Assim, no mercado de crenças, as ações da cultura científica vêm subindo paulatinamente. Dependendo do contexto, os investimentos privilegiam diferentes aspectos da atividade científica - como o raciocínio, o linguajar, a imaginação, o aparato conceitual, o sistema de informação, a metodologia, os instrumentos, os procedimentos, as instituições, a especialização, a hierarquização, as descobertas, as aplicações e suas potencialidades. O termo cultura parece englobar esses diversos aspectos, articulando-os numa rede de significações em que cada elemento se articula e se reforça com os outros.

Neste artigo procuramos contrapor a tendência de tratar a cultura científica como um conceito unívoco, ou seja, como se ela fosse igual em toda parte e em qualquer época. Para tanto, enfocamos quatro diferentes formulações expressivas de diferentes momentos da história brasileira. Nosso objetivo não é elencar diferentes formulações por mera curiosidade, mas evidenciar a transformação de visões sobre a ciência e seu papel na sociedade. Nosso interesse é conhecer melhor o repertório de noções de cultura científica, procurando mostrar distintas perspectivas e seus contextos, a fim de resgatar a dimensão histórica do processo de construção do papel que a ciência desempenha em nossa época.

Abordamos quatro formulações de autores bastante influentes no âmbito das políticas científicas e educacionais brasileiras: Miguel Ozorio de Almeida, Anísio Teixeira, Maurício Rocha e Silva e Carlos Vogt. Em diferentes períodos e contextos, esses quatro personagens atuaram na formulação e na articulação de políticas para fazer valerem suas visões na gestão pública para o desenvolvimento da ciência no Brasil. Nesse sentido, objetivamos discutir permanências e transformações referentes ao delineamento de uma concepção ampla, como é o caso da cultura científica.

Miguel Ozorio e, sobretudo, Anísio Teixeira já receberam a atenção de diversos estudiosos e tiveram suas obras analisadas sob diversos aspectos. Nosso foco aqui são as concepções de cultura científica e, assim, deixamos de lado vários outros aspectos importantes de suas ideias. Em função disso, focamos nossas análises nas obras mais significativas dos autores sobre a questão. Ao longo de suas vidas, eles reiteraram suas visões sobre a cultura científica, mas também reajustaram alguns aspectos. Não aprofundamos aqui os detalhes desses reajustes e modificações. O que retratamos são flashes de expressões influentes nos períodos em que foram publicadas.

\section{Mentalidade científica na visão de Miguel Ozorio de Almeida}

Miguel Ozorio de Almeida (1890-1953) era fisiologista e professor da Faculdade de Medicina e foi reitor da Universidade do Distrito Federal. Juntamente com seu irmão, Álvaro Ozorio, teve papel de destaque na institucionalização da ciência no Brasil, como um dos principais 
fundadores da Academia Brasileira de Ciências, que presidiu de 1929 a 1931. Foi também presidente da Academia Brasileira de Letras e diretor do Instituto Oswaldo Cruz.

A maioria dos escritos de Miguel são artigos científicos no campo da fisiologia. Porém, por estar à frente de associações envolvidas com política científica e preocupar-se com a difusão da cultura científica, publicou também conferências e ensaios mais gerais sobre a ciência e seu papel na cultura, além de biografias de personagens importantes na história da ciência. Esses textos foram agrupados em dois livros: Homens e coisas de ciência, publicado em 1925, e $A$ vulgarização do saber, de 1931. Em nossa análise, focalizamos os capítulos que tratam diretamente da cultura científica. São eles: "A mentalidade científica no Brasil" (1925), do primeiro, e, do segundo, "A alta cultura e sua organização", que foi publicado em 1931, mas se trata da transcrição de uma conferência realizada em 1925, na Associação Brasileira de Educação.

Sobre a mentalidade científica, o autor assevera que "nosso meio ainda não é dos mais propícios ao desenvolvimento máximo da cultura científica" (Ozorio de Almeida, 1925, p.205). Essa lacuna ou atraso é o que ele procurava reverter. Discute então as supostas razões dessa situação e delineia as exigências para o aprimoramento da cultura científica. A seu ver, a raiz do problema não estava, como haviam sugerido alguns de seus contemporâneos, na falta de "capacidade da raça", mas no modelo de saber que as inteligências nacionais haviam perseguido. Isso transparecia, primeiramente, na ênfase no conhecimento utilitário, que não percebia que sua potência dependia do investimento na ciência pura e desinteressada. E em segundo lugar, quando raramente essa ciência pura era perseguida, o modelo era o da história natural, baseada na observação e classificação, e não na física, na matemática ou nas ciências experimentais.

No primeiro caso, o problema vislumbrado estava tanto no ensino superior, voltado tão somente para a formação de profissionais liberais (médicos, juristas, engenheiros), quanto no ideário positivista que, apesar de ser também crítico da tradição bacharelesca, tinha o "conhecimento útil" como meta da ciência. Miguel Ozorio de Almeida e seus colegas da Academia Brasileira de Ciências se articulavam e escreviam em contraposição a essas duas tradições.

Para Ozorio de Almeida, os grandes ideais do país dependiam da formação de uma elite dotada da "alta cultura", preparada para compreender seus grandes problemas e atuar na realidade de maneira efetiva.

Para o autor, um dos grandes problemas nacionais era a falta de preparo da elite dirigente, a qual não tinha condições de resolver problemas sociais, administrativos e técnicos, muito menos as grandes questões morais da nacionalidade. A seu ver, precisava ser mudado o perfil da classe dirigente.

Se na sua época o idealismo era criticado devido ao desinteresse pelos problemas cotidianos, Ozorio de Almeida defende um idealismo prático, que seria típico de homens de alta cultura. Para a formação dessa elite, seria necessário fomentar estudos superiores com mentalidade científica e não restritos à formação profissional.

Além de tratar da necessidade de outro modelo da educação em todas as áreas, Ozorio de Almeida contesta o modelo de pesquisa científica prevalecente no seu tempo. Os naturalistas são por ele descritos como cientistas cuja prática requeria basicamente memória extensa e segura, principalmente visual, boa observação e paciência inesgotável para sistematização dos 
seres de variedade quase infinita. Para ele, a história natural, que fora o carro-chefe da ciência brasileira, exigia pouco do raciocínio, apesar da virtude de criar qualidades de disciplina e ordem. A nosso ver, essa categorização pode ser interpretada como uma divergência interna com a pequena comunidade de pesquisadores de então, provavelmente uma disputa pelo apoio e autoridade que a mais antiga instituição científica do Brasil - o Museu Nacional - desfrutava.

Para explicar as implicações desse modelo de ciência na cultura e as necessidades de contrapô-lo, Ozorio de Almeida (1925, p.214) faz uma distinção entre dois tipos de inteligências científicas. Segundo ele, "há inteligências possuidoras de uma especial capacidade de aprender um grande número de fatos, sem, entretanto, bem alcançar ideias abstratas, afastadas do mundo objetivo", que ele classifica como inteligências amplas e superficiais. Mas era o outro tipo, o da inteligência estreita e profunda, de que prescindíamos e deveríamos cultivar "mentes que se perdem quando é grande o número de noções com as quais têm que lidar, mas que em compensação são capazes de se aprofundar, em um círculo reduzido de ideias, a um ponto cada vez mais longínquo e árduo" (p.214).

Trata-se de um tipo de inteligência rara e que, segundo ele, se assemelha ao que Pascal chamava de "espírito de finura", mentes que na grande multiplicidade de fenômenos sentem os princípios e distinguem os valores. De acordo com Ozorio de Almeida, precisávamos cultivar pessoas aptas a acompanhar, passo a passo, complicadas demonstrações, conservando absoluto rigor de lógica no encadeamento dos raciocínios, sem perder outras propriedades de sua inteligência.

Vale ressaltar que Ozorio de Almeida escreveu não só para seus pares, intelectuais ou gestores. Vários de seus escritos almejavam público amplo. Sua preocupação com a popularização da ciência transparece no esforço de alcançar, com estilo acessível, os leitores de jornais e revistas, como também no envolvimento da discussão teórica sobre o papel da divulgação científica como, por exemplo, com a publicação, em 1931, do livro A vulgarização do saber, no qual ele defende a utilidade de pôr o grande público a par do movimento científico (Massarani, Moreira, 2004):

a vida moderna está cada vez mais dependente da ciência e cada vez mais impregnada dela. Não são só as pessoas cujas profissões reconhecidamente têm uma base científica, como a medicina ou a engenharia, que têm interesse em estar mais ou menos em permanente contato com diferentes ciências. Hoje, todas as indústrias, a agricultura e um grande número de outras profissões sofrem uma evolução rápida, devido à introdução dos métodos e processos científicos. A técnica moderna evolui para um estado racional, muito mais preciso e de rendimento muito maior. A difusão científica traria como resultado a familiaridade de todos com as coisas da ciência e, sobretudo, uma confiança proveitosa nos métodos científicos, uma consciência esclarecida dos serviços que estes podem prestar (Ozorio de Almeida, 1931, p.236).

As pessoas que possuíssem uma cultura científica poderiam perceber as relações menos imediatas entre os progressos científicos e o bem-estar coletivo e apoiar iniciativas que o vulgo desconsiderava. Dessa forma, o maior objetivo da difusão da cultura científica em ambientes "isolados" não seria tanto a divulgação de informações, novidades ou explicações, mas a compreensão das linhas essenciais da ciência e de seu progresso, além das chances de, aguçando a curiosidade, despertar novas vocações. A cultura científica que Ozorio de 
Almeida queria promover se referia ao conhecimento de como a ciência avança (ou poderia avançar, se alicerçada no espírito de finura daqueles dedicados à ciência pura), como também ao reconhecimento social e governamental acerca da importância das instituições científicas (associações, laboratórios e institutos de pesquisa) e de seus papéis para o progresso da nação.

Por fim, um aspecto da mentalidade científica que será enfatizado mais tarde por Ozorio de Almeida, quando em 1935 assume a presidência da Comissão Brasileira de Cooperação Intelectual, é o dever do intelectual brasileiro em colaborar para o desenvolvimento da ciência "universal" e a "evolução da humanidade". A cooperação entre os países era defendida como algo fundamental para o progresso intelectual universal (Fonseca, Maio, 2004; Souza, jul. 2011).

Talvez a obra de um único autor profícuo como Ozorio de Almeida já fosse suficiente para visualizar importantes variações da noção de cultura científica ao longo do tempo e entre diferentes audiências. No entanto, tal visualização é enriquecida quando se lança luz sobre personagens de destaque em outros círculos, como é o caso de Anísio Teixeira.

\section{Anísio Teixeira e o espírito científico}

Anísio Spínola Teixeira (1900-1971) é figura emblemática na história da educação brasileira. Natural de Catité, Bahia, formou-se em direito no Rio de Janeiro, em 1922. Iniciou sua carreira de pedagogo e administrador público como inspetor-geral de ensino da Bahia. Em 1928, foi estudar na Universidade de Columbia, em Nova York, onde obteve o título de mestre e conheceu o educador John Dewey. Em 1931, tornou-se secretário da Educação do Rio de Janeiro e realizou ampla reforma na rede de ensino, do primário ao superior. Ele foi idealizador e reitor da Universidade do Distrito Federal no início dos anos 1930. Na década de 1950, esteve à frente do Instituto Nacional de Estudos e Pesquisas Educacionais (Inep) e da Coordenação de Aperfeiçoamento de Pessoal de Nível Superior (Capes) e, no início dos anos 1960, da criação da Universidade de Brasília (UnB), da qual foi reitor em 1963 e $1964 .{ }^{1}$ Sua concepção de cultura científica esteve presente nas discussões e no delineamento de boa parte dessas iniciativas (Mendonça, 2002; Nunes, 2000).

Seus escritos tratam, principalmente, de sistemas de ensino, educação pública, democratização, pesquisa em educação, ensino superior e formação de professores. Em todos eles, Anísio procura fundamentar de forma clara uma série de propostas concretas de transformação da realidade educacional brasileira.

Grande parte dessas propostas ancora-se na necessidade de incorporação de uma perspectiva científica em diferentes frentes: nas universidades, na formação de professores, na racionalização do sistema educacional, na avaliação da educação e na democratização da sociedade brasileira. Nesse estudo focamos em "Ciência e humanismo" (Teixeira, 1955), que ele publica em 1955 como diretor do Inep, e "O espírito científico e o mundo atual" (Teixeira, 2006), publicado, originalmente, em 1959 na Revista Brasileira de Estudos Pedagógicos. Esses artigos foram, posteriormente, agrupados em duas coletâneas. ${ }^{2}$ Teixeira raramente se vale da expressão "cultura científica", mas discute com frequência sobre o espírito científico e sobre o espírito universitário, que revelam sua concepção sobre os valores e o papel da ciência na cultura.

De forma resumida, o espírito que Teixeira se empenha em promover se caracteriza pela postura autocrítica, antidogmática e democrática que, alicerçada numa metodologia 
de investigação, experimentação e reavaliação, possibilitaria um seguro e contínuo aperfeiçoamento da resolução dos problemas humanos. Na visão de Anísio, o espírito científico tem caráter evolutivo e progressivo, tendo herdado do pensamento grego clássico características cognitivas como a lógica, o raciocínio hipotético-dedutivo e a plausibilidade, que tanto têm contribuído para a evolução do pensamento humano. Por isso, a seu ver, o "milagre grego" significou um salto de libertação do poder mental do homem e da afirmação do espírito humano. Com o advento da ciência moderna e de uma concepção pragmática do conhecimento como instrumento, o fazer passou a ser essencial para o pensar. De acordo com essa reconstrução histórica, as necessidades materiais se valeram, a partir daí, de uma inteligência realística. No entanto, segundo Teixeira, as necessidades da alma ainda se apoiam no pensamento mítico e alimentam dicotomias que deveriam ser superadas, tais como as oposições entre teoria x prática, especulação x empiria e espiritual x material.

Para Teixeira, a superação de dualismos dar-se-ia por meio da ampliação dos domínios da ciência para outros campos, já que ela seria capaz de aprimorar os valores por seu caráter antidogmático e autocorretivo.

A extensão da ciência ao mundo dos valores irá completar a obra da ciência, iluminando a visão prática e terrena da vida, que ela já produziu, ou está inspirando, com o sentimento das riquezas morais e espirituais da nova existência do homem no mundo por ele conquistado e domesticado (Teixeira, 2006, p.146).

A democracia também se beneficiaria da postura científica, que traria progressivo domínio dos problemas da vida.

Do mesmo modo que damos como certos e seguros os fins mais óbvios da vida: saúde, alimentação, casa, vestuário - os chamados fins materiais da vida - também haveremos de chegar a dar segurança e controle aos chamados fins superiores ou espirituais: o do governo da liberdade humana, o da realização da fraternidade e o da felicidade pessoal e coletiva (p.136).

Teixeira propunha a profissionalização das ações de pesquisa e, principalmente, da educação científica, como uma via de extensão do espírito científico à cultura geral, por meio de políticas para a inclusão de ciência em todos os níveis de ensino.

A educação científica promoveria liberdade, segurança e progresso social.

O aparente, só aparente, efeito desagregador da ciência, em sua aplicação à vida, decorre de que adotamos (quando adotamos) o método científico em nossos problemas de ordem material, e métodos pré-científicos ou anticientíficos em nossos problemas sociais, políticos e morais... Qual não seria nosso progresso político e moral, no dia em que adotássemos o mesmo caminho nesses setores bem mais importantes para a vida humana (p.145).

Na perspectiva deweyneana, com a qual Anísio Teixeira se alinhava, o conhecimento é concebido como um instrumento. Contrariamente à ideia de uma erudição e de acervo, o conhecimento deveria ser pensado em termos das necessidades do presente, das possibilidades futuras e do desenvolvimento social. Isso fica claro, por exemplo, em seu discurso de inauguração da Universidade do Distrito Federal em 1935, no qual afirma querer conservar “o saber vivo e não morto, nos livros ou no empirismo das práticas não intelectualizadas. 
Trata-se de formular intelectualmente a experiência humana, sempre renovada, para que a mesma se torne consciente e progressiva" (Teixeira, 1998, p.88).

A modernização da universidade tinha grande importância, pois, a seu ver, ela seria o centro irradiador de cultura. Em oposição à universidade clássica, que se assemelhava a um monastério, isolada da sociedade, a universidade moderna deveria ser o centro da vida social e assumir a função de alavanca do progresso econômico e dos avanços culturais. Seus professores e estudantes deveriam ser capazes não apenas de conhecer o saber existente, mas de desdobrá-lo, isto é, encontrar meios de fazer com que os novos avanços (cultural e material) pudessem ser aprimorados e incorporados pela sociedade.

Modernizar a universidade implicava racionalizá-la, substituindo sua estrutura antiquada, que emperrava o desenvolvimento, e colocando no cerne da vida universitária a cultura científica e tecnológica. Vale observar a dimensão pragmática de sua visão de ciência. A seu ver,

a nova ciência já não era uma ciência de especulação ou de exegese e interpretação do conhecimento existente no passado, mas ciência criadora e extraordinariamente fecunda em consequências culturais e tecnologias para a solução dos problemas materiais relacionados com o poder e o enriquecimento humano (Teixeira, 2005, p.191).

Contudo, o funcionamento dessa universidade modernizada com a perspectiva científica e tecnológica dependia da melhoria do conjunto do sistema educacional que, por sua vez, incluía a melhoria da formação dos professores a ser efetuada pela universidade. Daí o esforço simultâneo de Teixeira em duas frentes: na implementação do direito de todos a um ensino básico de qualidade e na reforma universitária que potencializasse a transformação da cultura e o desenvolvimento social.

A reforma universitária dependia de uma mudança de mentalidade, de estrutura administrativa e de modelo de ciência, com estudos aprofundados (em contraposição à superficialidade e à falta de sistematização do autodidatismo que predominavam), planejamento das investigações e integração das áreas e níveis de ensino (Carli, Oliveira, 2009). Porém, a base dessas mudanças estava na metodologia científica, que lhe forneceria segurança e otimismo para assumir novas responsabilidades.

O homem está com responsabilidades novas em toda a sua vida. Ele ensaia no mundo moral e social, senão com a mesma audácia, por certo sob o influxo dos mesmos princípios que lhe permite experimentar no mundo material ... Se as conclusões podem ser e são falíveis, o método é sempre digno de confiança. O ato de fé do homem moderno esclarecido não repousa nas conclusões da ciência, repousa no método científico, que lhe está dando um senso novo de segurança e de responsabilidade (Teixeira, 2005, p.146).

Anísio Teixeira manteve interlocução com diversas audiências e autores, entre eles Maurício Rocha e Silva, cuja concepção de "cultura científica" abordaremos a seguir. Uma coletânea de cartas trocadas entre os autores foi publicada como livro em 1968. Dialogar sobre a obra ${ }^{3}$ de Rocha e Silva foi um pretexto de que se valeram para tratar de problemas fundamentais da filosofia, expondo seus pontos de vista que, mesmo divergindo em alguns aspectos, se encontravam em muitos outros, não como concordância que ali se finalizava, mas que, antes, instigava novos diálogos. 


\section{O progresso da ciência e da cultura na visão de Maurício Rocha e Silva}

Maurício Rocha e Silva (1910-1983) nasceu no Rio de Janeiro, mas fez carreira em São Paulo, após formar-se na Faculdade de Medicina do seu estado natal. Na época, estudos experimentais estavam restritos ao Instituto Oswaldo Cruz no Rio e a grupos como o de Ozorio de Almeida. Entre 1937 e 1957, foi pesquisador do Instituto Biológico de São Paulo, onde descobriu um novo princípio ativo, batizado de bradicinina (brady= lento e kinesia = movimento), que serviu de base ao desenvolvimento de medicamentos anti-hipertensivos.

No campus de Ribeirão Preto da Universidade de São Paulo, onde foi professor de 1957 a 1981, desenvolveu um centro de pesquisas na área de farmacologia e bioquímica. A comunicação da descoberta da bradicinina, assinada por Rocha e Silva, Wilson T. Beraldo e Gastão Rosenfeld, foi publicada em 1949 no número inaugural da revista Ciência e Cultura, da recém-fundada Sociedade Brasileira para o Progresso da Ciência (SBPC). Foi publicada também no American Journal of Physiology, o que lhe rendeu notoriedade internacional devido ao impacto desse trabalho na fisiologia (SBPC, 1998; Rocha e Silva, 2005).

Rocha e Silva foi um dos fundadores da SBPC, na qual exerceu diversos cargos de diretoria durante duas décadas (1948-1969), defendendo principalmente a bandeira da ciência pura (entendida como ciência experimental) e o alinhamento pesquisa-ensino nas universidades.

As publicações de Rocha e Silva são prioritariamente nas áreas da fisiologia e da farmacologia. No campo da filosofia, ou mais especificamente da filosofia da ciência, publicou quatro obras: Lógica da invenção (1965); Diálogo sobre a lógica do conhecimento (1968); Ciência e humanismo (1969); A evolução do pensamento científico (1972). De forma geral, esses escritos ecoam a visão de um grupo de cientistas brasileiros que constituiu a SBPC como sociedade para a promoção da cultura científica no Brasil.

Ciência e humanismo consta de duas partes, "A evolução da ciência" e "As duas culturas", compostas de ensaios e conferências relacionando ciência e arte, e elaboradas para um evento vinculado à Nona Bienal Internacional de São Paulo. Mais do que filosofia, são ensaios sobre política científica e a promoção de seu papel no contexto social e político.

Rocha e Silva enfatiza a cultura científica como via de desenvolvimento e progresso, e os exemplos que apresenta caracterizam a ciência como o estágio mais evoluído desse crescimento. O autor tem como um de seus objetivos demonstrar os caminhos imbricados e tortuosos da evolução da ciência na história mundial. O Brasil deveria mirar-se e almejar esse desenvolvimento, mas isso demandava a superação do "atraso na mentalidade do país". Ainda que as artes servissem como alerta e conscientização, a superação só se daria, a seu ver, com o avanço da ciência:

Uma certa mentalidade suburbana tende a restringir a cultura nacional ao estudo de pequenos eventos locais, folclóricos, linguísticos ou musicais, com a ideia de que repetindo indefinidamente os motivos da nossa miséria, algum dia alguém poderá ouvir e nos dar a mão para nos tirar do subdesenvolvimento, tão bem descrito nas canções premiadas, nos refrãos da UNE, no samba, na bossa nova. É claro que, com isso apenas, a perturbação das causas nos levará à repetição indefinida dos mesmos refrãos, das mesmas canções, que sobem aos céus como o triste resmungo de escravos diante de seus algozes (Rocha e Silva, 1969, p.20). 
De acordo com sua interpretação histórica do pensamento científico, a inércia e os temores geraram o atraso e emperraram a eclosão do verdadeiro espírito científico, "que teve de esperar a sua vez, nas masmorras da idade média, até que afrouxassem as imposições dos poderes dominantes" (p.38).

Abrir aquela "porta pesada" requereu, segundo ele, esforços por parte dos cientistas, principalmente para convencer os outros do valor da atividade científica. As experiências de salão, realizadas por cientistas diretamente para o público, principalmente no século XVII e ainda no século XIX, são citadas como exemplo desses esforços. Rocha e Silva faz uma analogia entre essas práticas do passado e o que ainda era preciso fazer no Brasil para referirse à situação dos cientistas em países subdesenvolvidos, frente às incompreensões sobre a importância da ciência pura para o desenvolvimento. Estando à frente da SBPC, defendeu o investimento em laboratórios, na pesquisa pura e experimental. Para tanto, era preciso vencer a "inércia da mentalidade coletiva" que "não raro se encontrava entre indivíduos de grande reputação" (Rocha e Silva, 1969, p.83), também entre cientistas, mas, especialmente, na figura de alguns professores catedráticos.

Rocha e Silva retoma o debate sobre As duas culturas e uma segunda leitura, de Snow, para traçar o mapa dos problemas do contexto intelectual brasileiro. Afirma que homens de formação humanística, que se encontravam nos governos dos países em desenvolvimento, ignoravam quase tudo de ciência, e da ideia que dela fazem derivava uma "propaganda tendenciosa" em prol da "pesquisa tecnológica, que levasse imediatamente à fabricação de comodidades". O fosso entre as duas culturas seria agravado no Brasil pela inadequação das universidades, que se constituíam como "nada além de aglomerados de escolas profissionais". (Rocha e Silva, 1969, p.124-127).

Na sua visão, a cultura científica não se distinguiria da humanista, simplesmente porque a primeira seria a evolução natural da segunda, o que lhe daria razão para a defesa enfática da cultura científica vista como fonte de progresso.

Progresso é investigação científica e pode-se dizer que, nos últimos 100 anos, o homem progrediu mais do que nos 100 séculos anteriores, desde os primeiros vestígios da civilização na face da Terra. Tudo nos indica que esse progresso vai continuar em escala autocatalítica, isto é, nos próximos dez anos é possível que o progresso do homem seja da ordem de grandeza dos últimos 100 anos, e assim por diante (p.124).

Justamente no período de endurecimento da ditadura militar, Rocha e Silva apregoa o caráter libertador da ciência como algo muito mais relevante que manifestações políticas em praça pública. Na sua visão, era a investigação científica pura, que ele considerava ser a fonte de toda a tecnologia industrial, o que de fato revolucionava o mundo. Na sua campanha por mais recursos e reconhecimento para a atividade científica, afirma que talvez ainda pior que a perseguição a alguns cientistas tidos como subversivos era a condenação pela falta de financiamento, que ameaçava a expansão da cultura científica (p.88). Na primeira década do regime militar, a relação da $\mathrm{SBPC}^{4}$ com o governo foi dúbia, pois ao mesmo tempo em que criticava o cerceamento da liberdade e a "evasão de cérebros", ela também celebrou o apoio do governo militar às atividades científicas, ainda que esses investimentos pudessem ser considerados tentativas de legitimação do regime (Fernandes, 2000; Fonseca, 2012). 
A defesa de Rocha e Silva da liberdade de expressão se conjugava na defesa da liberdade de pensar e expressar argumentos racionais, sob qualquer regime político. Dessa forma, se colocava a estrutura política como mera circunstância no desenvolvimento de uma racionalidade científica, dando mais prestígio à ciência do que à política (Fonseca, 2012). Ainda que suas posições políticas frente ao regime não fiquem claras, Rocha e Silva procurava de forma bem enfática reforçar a valorização do papel da ciência e sua potencialidade para a determinação dos rumos da cultura e das nações, dando relevância à centralidade da ciência para se pensar no progresso e desenvolvimento da nação.

\section{Carlos Vogt e o movimento da cultura científica}

A quarta concepção de cultura científica que selecionamos para cotejar é mais atual e uma boa expressão das questões em pauta em debates contemporâneos sobre a relação entre ciência e sociedade. Como expressão dessa visão, tomamos alguns escritos de Carlos Alberto Vogt.

Nascido em 1943, linguista de formação e doutor em ciências pela Universidade Estadual de Campinas, Vogt foi reitor dessa universidade entre 1990 e 1994, presidente da Fundação de Amparo à Pesquisa do Estado de São Paulo de 2002 até 2007 e secretário de Ensino Superior do Estado de São Paulo entre 2007 e 2010.

Vogt é professor titular na área de semântica argumentativa e coordenador do Laboratório de Estudos Avançados em Jornalismo. Ele coordena projetos de pesquisa sobre divulgação científica e percepção pública da ciência e foi editor-chefe de Ciência e Cultura, da SBPC entre 2002 e 2007. O autor publicou livros, artigos e ensaios em revistas nacionais e internacionais, entre elas a revista de divulgação científica ComCiência, da qual é diretor de redação.

De sua profícua produção, escolhemos analisar o artigo "A espiral da cultura científica" (Vogt, jul. 2003). Além desse, outros tratam do tema, tal como o capítulo "Ciência, comunicação e cultura científica" no livro Cultura científica: desafios (2006), do qual é organizador. O texto "Espiral da cultura científica" foi publicado em 2003 na revista ComCiência, e, no contexto das produções de Vogt, parece gestar uma estrutura de organização seminal para outros textos e publicações. Nesse, o autor organiza e apresenta de forma esquemática seu entendimento sobre a dinâmica da cultura científica.

Vogt incorpora a dimensão sociológica e antropológica ao tratamento da cultura científica, ou seja, destaca os processos de interação e regulação social, bem como a significação simbólica na constituição da ciência. Vista assim, a atividade científica engloba diferentes atores, características, audiências, instituições e estilos. A ênfase de Vogt é na comunicação e difusão do saber. Ele mostra como são limitadas e problemáticas as noções usuais de "alfabetização científica", "popularização/vulgarização da ciência" e "percepção/compreensão pública da ciência". Vogt retoma essa discussão na apresentação da coletânea Cultura científica: desafios, em que mostra como

por detrás da estratégia espontânea e tradicional da comunicação das ciências e das tecnologias, distingue-se a imposição determinada por essa modalidade direta, segundo a qual o público teria de compreender a ciência (public understanding of science), teria de estar consciente de sua importância (public awareness of science), teria de incorporar um nível de cultura científica indispensável (science literacy) (Vogt, 2006, p.23). 
Enquanto as noções de "alfabetização científica" e de "difusão/popularização" da ciência passam a ideia de que ela deve ser apenas transmitida ao público leigo, as expressões "percepção/compreensão pública da ciência" supõem que o problema estaria na falta de compreensão, na ignorância ou desinteresse do vulgo. Em contraposição a esses modelos - que vêm sendo analisados criticamente por sua vinculação à concepção de deficit cognitivo, como se a chamada cultura popular ou o conhecimento do senso comum pecassem por suas lacunas de conhecimento científico, desconsiderando suas diferenças e resistências como legítimas -, a noção de cultura científica seria mais adequada para lidar com a dinâmica da ciência. A expressão "cultura científica" contém a ideia de que desenvolvimento científico é um processo cultural,

seja ele considerado do ponto de vista de sua produção, de sua difusão entre pares ou na dinâmica social do ensino e da educação, ou ainda, do ponto de vista de sua divulgação na sociedade como um todo, para o estabelecimento das relações críticas necessárias entre o cidadão e os valores culturais de seu tempo e de sua história (Vogt, 2006, p.25).

Vogt propõe um modelo espiral de constituição da cultura científica, como forma de melhor compreender sua dinâmica. Para tanto, delineia quatro quadrantes, cada um composto por um conjunto de elementos, sobre os quais se forma uma espiral que, partindo do primeiro quadrante (da produção e difusão da ciência), progressivamente vai ao segundo (do ensino de ciência e da formação do cientista) e ao terceiro (do ensino para a ciência), chegando ao último (da divulgação da ciência). Ainda que pensados como evolução, o autor reconhece nos quadrantes diferentes audiências, atores, características, instituições e estilos mediando a atividade científica, o que diferencia esse modelo de outros modelos lineares e baseados na ideia de deficit. A seu ver, o movimento espiral representaria a dinâmica constitutiva das relações inerentes e necessárias entre ciência e cultura, atravessando os quatro quadrantes, mas de forma ascendente.

A espiral da cultura científica, ao cumprir o ciclo de sua evolução, retornando ao eixo de partida, não regressa, contudo, ao mesmo ponto de início, mas a um ponto alargado de conhecimento e de participação da cidadania no processo dinâmico da ciência e de suas relações com a sociedade, abrindo-se com a sua chegada ao ponto de partida, em não havendo descontinuidade no processo, um novo ciclo de enriquecimento e de participação ativa dos atores em cada um dos momentos de sua evolução (Vogt, 2006, p.25).

Convém notar como, na visão de Vogt, a cultura científica é crítica e evolutiva. As pessoas com tal formação, ou que incorporaram seus valores e perspectivas, saberiam reconhecer as limitações da ciência e não se deixariam iludir sobre as mitificações que envolvem sua publicidade. Essa é uma interessante idealização do que deveria ser a atividade científica. Assim como nos casos de Miguel Ozorio de Almeida e Anísio Teixeira, sua abordagem permanece, a nosso ver, mais prescritiva do que descritiva e analítica. Como apontamos no início deste artigo, nosso interesse aqui não é discutir ou averiguar quão idealizadas são essas noções de cultura científica, e sim conhecer melhor seu repertório. Além disso, as valorizações têm também implicações na percepção e interpretação do desenvolvimento da ciência. Ao reconsiderar os processos de produção, difusão, ensino e a dinâmica social que envolve tal 
cultura, Vogt traz à pauta de discussões outra forma de inserção da ciência na vida social, com transformações no modelo de fazer ciência e das relações de poder ali envolvidas. Como ele mesmo chama a atenção, o fato de democratizar escolhas científicas e tecnológicas implica não apenas compartilhar o conhecimento, mas também o poder.

A expressão "cultura científica", conforme Vogt apresenta, é um conjunto de discursos, instituições, práticas, artefatos, técnicas, crenças, posturas, valores e formas de vivenciá-los (éthos), de organizar os grupos e suas relações. A percepção da dinâmica cultural e de seus processos de ressignificação ajuda a entender o empreendimento científico, mas há que reconhecer também que sua abrangência traz consigo certa imprecisão.

\section{Considerações finais}

As quatro concepções focalizadas neste artigo não são de forma alguma estanques. Há interseções, acumulações, e algumas diferenças foram forjadas a partir de situações vivenciadas anteriormente. Ainda quando se valem de sentenças semelhantes, alguns sentidos foram-se alterando, assim como as ênfases, enquanto certos pressupostos e ordenações mais ou menos visíveis permaneceram, como o combate à visão de mundo não científica dos incrédulos e resistentes às promessas da ciência. Embora a pregação de Miguel Ozorio de Almeida, Anísio Teixeira e Maurício Rocha e Silva sobre a ciência pura e desinteressada já não ecoe muito na esfera pública, ela foi peça fundamental na institucionalização da ciência no Brasil e ainda se faz escutar em algumas instâncias. Com as reformas das universidades e a criação de institutos de pesquisa, a ciência especializada foi legitimada e profissionalizada, e a atuação de Teixeira e Rocha e Silva teve grande importância nesse processo. O CNPq e a Capes foram fundamentais na consolidação de um sistema nacional de financiamento da pesquisa e da pós-graduação.

Há também uma linha atando a ênfase que Teixeira dava à dimensão antidogmática da perspectiva científica ao destaque que Vogt imprime à sua característica crítica, ainda que, no primeiro caso, a contraposição fosse ao dogmatismo religioso (e à reação dos católicos à expansão da educação pública e laica) e, no segundo caso, à inconsequência de cientistas ingênuos ou prepotentes.

Nas quatro visões, há uma preocupação comum em envolver o grande público, ainda que em Ozorio de Almeida ela ressoe como formação de uma audiência que sustentasse uma elite científica que atuaria para o bem de todos, em Teixeira ela guarde o sentido iluminista de educação e libertação da população isolada e excluída, em Rocha e Silva ela busque prestígio e apoio para financiamentos de uma ciência redentora e em Vogt transpareça um cuidado com a significação política da transmissão de conhecimento e uso da informação em via única. Neste último, o viés é o da participação ativa do cidadão no amplo processo de transformação cultural.

Há pontos que podem ser entrevistos nas práticas e nos discursos de associações científicas contemporâneas e que são relevantes na concepção de um deles apenas, como, por exemplo, a ideia de que ciência se faz com mentes brilhantes a descobrir, que está clara em Ozorio de Almeida e que hoje embasa várias ações de "caça a jovens talentos". Diferentemente, Teixeira e Vogt se preocupam mais com a democratização do acesso e ampliação da participação de 
novos grupos sociais do que com a seleção de uma nova elite científica. Pode-se ver assim que, além das recorrências, como a defesa da centralidade da ciência para a vida cultural e desenvolvimento social e a militância em prol da disseminação das posturas científicas, há também diferenças significativas entre as quatro formulações esboçadas neste artigo. Elas não são complementares, mas também não chegam a colocar seus autores em campos antagônicos.

A noção de cultura científica envolve desde pressupostos epistemológicos, práticas, circunstâncias históricas até valores ligados à ciência. Essas quatro concepções de cultura científica não chegam a compor nem uma breve história dessa noção entre nós, mas, a nosso ver, revela relances de momentos e atores que podem ajudar a compô-la.

\section{NOTAS}

${ }^{1}$ Nos dois primeiros anos de funcionamento da UnB, Anísio foi vice-reitor. Ele havia sido convidado para ser o primeiro reitor, mas, segundo Salmeron (1999), não aceitou o cargo porque não tinha intenção de morar em Brasília por longos períodos. Ele só assumiu a reitoria quando seu discípulo e colega Darcy Ribeiro deixou o cargo para se tornar ministro da Casa Civil do governo de João Goulart. Com o golpe de 1964, o projeto foi interrompido e Anísio afastado.

2 Vários argumentos e trechos desses artigos são retomados em escritos posteriores. Esses dois artigos foram conjugados com outros ensaios no livro Educação e o mundo moderno (1969). Os artigos que tratam do ensino superior foram reunidos na coletânea Educação e universidade (1998) e Universidade de ontem e de hoje (1998).

${ }^{3}$ Em 1965, Rocha e Silva publicara Lógica da invenção. Este livro deu origem a outro, que consistiu na coletânea de cartas trocadas entre Anísio Teixeira e Maurício Rocha e Silva entre 1965 e 1966, nas quais Teixeira comenta as questões que o intrigavam no recém-publicado livro.

${ }^{4} \mathrm{O}$ fórum da SBPC, especialmente suas reuniões anuais, restou como um espaço livre de debates mesmo nos anos de chumbo da ditatura. Cientistas sociais, estudantes e o público em geral se associaram, o que gerou um grande crescimento e fez com que suas reuniões ganhassem traços de mobilização popular e de luta contra o regime ditatorial em meados da década de 1970.

\section{REFERÊNCIAS}

CARLI, Sandra; OLIVEIRA, Bernardo J. Reformas para modernizar a universidade: as visões de Risieri Frondizi e Anísio Teixeira. In: Vidal, Diana G.; Ascolani, Adrián (Org.). Reformas educativas no Brasil e na Argentina: ensaios de história comparada da educação (1820-1980). São Paulo: Cortez. p.205-239. 2009.

DONNELLY, James F.

The "humanist" critique of the place of science in the curriculum in the nineteenth century, and its continuing legacy. History of Education, v.31, n.6, p.535-555. 2002.

FERNANDES, Ana Maria.

A construção da ciência no Brasil e a SBPC. Brasília: UnB. 2000.

FONSECA. Marina Assis.

Constituição de valores de ciência e cultura no Brasil - 1948-1988. Tese (Doutorado) - Faculdade de Filosofia e Ciências Humanas, Universidade Federal de Minas Gerais, Belo Horizonte. 2012.
FONSECA, Maria Rachel Fróes da; MAIO, Marcos Chor.

Miguel Ozorio de Almeida e o projeto de uma história científica e cultural da humanidade. História, Ciências, Saúde - Manguinhos, v.11, n.2, p.459-468. 2004.

KRANZBERG, Melvin et al. (Ed.). Innovation at the crossroads between science and technology. Haifa: Neaman Press. 1989.

MASSARANI, Luisa; MOREIRA, Ildeu de Castro. Miguel Ozorio de Almeida e a vulgarização do saber. História, Ciências, Saúde - Manguinhos, v.11, n.2, p.501-513. 2004.

MENDONÇA, Ana Waleska. Anísio Teixeira e a universidade de educação. Rio de Janeiro: Eduerj. 2002.

NUNES, Clarice.

Anísio Teixeira: a poesia da ação. Bragança

Paulista: Edusf. 2000. 
OLIVEIRA, Bernardo Jefferson de.

Francis Bacon e a fundamentação da ciência como tecnologia. Belo Horizonte: Ed. UFMG. 2002.

OZORIO DE ALMEIDA, Miguel.

A vulgarização do saber. Rio de Janeiro: Ariel. 1931.

OZORIO DE ALMEIDA, Miguel.

Homens e coisas de ciências. São Paulo: Ed. Monteiro Lobato. 1925.

PRICE, D.; SPIEGEL, I.

Science, technology and society. London: Sage. 1977.

ROCHA E SILVA, Maria Ignez.

Maurício Oscar da Rocha e Silva: o homem e suas circunstâncias. São Paulo: Lato Senso. 2005.

ROCHA E SILVA, Maurício.

Ciência e humanismo. São Paulo: Edart. 1969.

SALMERON, Roberto A.

A universidade interrompida: Brasília 1964-1965. Brasília: UnB. 1999.

SBPC.

Sociedade Brasileira para o Progresso da Ciência. Maurício Rocha e Silva. In: Cientistas do Brasil: depoimentos. São Paulo: SBPC. p.717-728. 1998.

SNOW, Charles Percy.

As duas culturas e uma segunda leitura. São Paulo: Edusp. 1995.

SOUZA, Letícia Pumar Alves de.

Por uma ciência universal: a atuação de intelectuais brasileiros no projeto de cooperação intelectual da Liga das Nações (décadas de 1920 a 1940). Simpósio Nacional de História -
Anpuh, 26., jul. 2011, São Paulo. Anais... São Paulo: Associação Nacional dos Professores Universitários de História. p.1-15. Disponível em: http://www.snh2011.anpuh.org/ resources/anais/14/1300803039_ARQUIVO_ TextoANPUH-2011.pdf. jul. Acesso em: 15 fev. 2012. jul. 2011.

TEIXEIRA, Anísio S.

O espírito científico e o mundo atual. In:

Teixeira, Anísio S. Educação e o mundo moderno. Rio de Janeiro: Ed. UFRJ. p.119-147. 2006.

TEIXEIRA, Anísio S.

Ensino superior no Brasil: análise e interpretação de sua evolução até 1969. Rio de Janeiro: Ed. UFRJ. 2005.

TEIXEIRA, Anísio S.

A função das universidades. In: Nunes, Clarice (Org.). Anísio Teixeira: a universidade de ontem e de hoje. Rio de Janeiro: Ed. Uerj. p.81-102. 1998.

TEIXEIRA, Anísio S.

Ciência e humanismo. Revista Brasileira de Estudos Pedagógicos, v.24, n.60, p.30-44. 1955.

VOGT, Carlos.

Ciência, comunicação e cultura científica. In: Vogt, Carlos (Org.). Cultura científica: desafios. São Paulo: Universidade de São Paulo; Fapesp. p.19-26. 2006.

VOGT, Carlos.

A espiral da cultura científica. ComCiência, n.45. Disponível em: http://www.comciencia.br/ reportagens/cultura/cultura01.shtml. Acesso em: 20 maio 2009. jul. 2003.

\section{$\rightarrow \rightarrow \rightarrow<<$}




\section{ERRATA}

No texto "Variações sobre a 'cultura científica' em quatro autores brasileiros", de Marina Assis Fonseca e Bernardo Jefferson de Oliveira, publicado em História, Ciências, Saúde Manguinhos, v.22, n.2, jan.-abr. 2015:

- na página 447, quinto parágrafo, primeira linha, onde se lê "Miguel Ozorio de Almeida (1890-1953) era fisiologista e professor da Faculdade de Medicina", leia-se "Miguel Ozorio de Almeida (1890-1953), fisiologista, era professor da Escola Superior de Agricultura e Medicina Veterinária";

- na página 448, primeiro parágrafo, segunda linha, onde se lê "diretor do Instituto Oswaldo Cruz", leia-se "diretor da Seção de Fisiologia do Instituto Oswaldo Cruz".

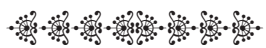

No texto da Nota de Pesquisa "A perícia médico-legal e o ensino: dissidências e discussões na Sociedade Brasileira de Neurologia, Psiquiatria e Medicina Legal”, de Ede Cerqueira, publicado em História, Ciências, Saúde - Manguinhos, v.22, n.2, jan.-abr. 2015:

- na página 642, terceiro parágrafo, última linha, onde se lê "SBNPML", leia-se "Serviço";

- na página 643, último parágrafo, segunda e terceira linhas, onde se lê "aulas teóricas. A cadeira prevaleceu", leia-se "aulas teóricas, prevalecendo";

- na página 644, segundo parágrafo, nona linha, onde se lê 'instituições se manifestaram contra a "implementação", leia-se 'instituições se manifestaram "no sentido de implementação"';

- na página 646, terceiro parágrafo, quarta e quinta linhas, onde se lê "e, possuindo caráter público", leia-se "e, já que esta possui caráter público".

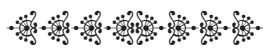

